\title{
Evidence-based practice training for health professionals in the Philippines
}

This article was published in the following Dove Press journal:

Advances in Medical Education and Practice

16 April 2014

Number of times this article has been viewed

\author{
Janine Margarita Dizon ${ }^{1,2}$ \\ Ryan Joseph Dizon ${ }^{3}$ \\ Jocel Regino ${ }^{4}$ \\ Alberto Gabriel ${ }^{5}$ \\ 'Center for Health Research and \\ Movement Science,University of \\ Santo Tomas, Manila, Philippines; \\ International Centre for Allied \\ Health Evidence, University of South \\ Australia, Adelaide, Australia; ${ }^{3}$ College \\ of Nursing, University of Santo Tomas, \\ ${ }^{4}$ Apolinario Mabini Rehabilitation \\ Center, University of Santo Tomas \\ Hospital, ${ }^{5}$ Department of Internal \\ MedicineOspital ng Maynila, Manila, \\ Philippines
}

\begin{abstract}
Evidence-based practice (EBP) is integral in the health care system whether in developed or developing countries. Thus, all health professionals need to be trained in EBP. An EBP training program was conducted to health professionals in a developing country, the Philippines. The health professionals (medical doctors and allied health professionals [physical therapists and occupational therapists]) were working in hospitals in Manila, Philippines. The program aimed to build capacity in EBP in terms of knowledge and skills. The EBP training program was conducted as a 1-day face-to-face training. Pre- and post-test measures of EBP knowledge and skills were taken prior to and immediately after the 1-day training, using the Fresno test of evidence-based medicine for the medical doctors and the Adapted Fresno test for the allied health professionals. The EBP training program resulted in significant improvements in knowledge and skills for both the medical doctors (change in pre- and post-Fresno test measures, 95\% confidence interval [CI]: 14.6-23.5; $P \leq 0.05$ ) and the allied health professionals (change in pre- and post-Adapted Fresno test measures, $95 \% \mathrm{CI}$ : 32.7-38.5; $P \leq 0.05)$. The EBP training conducted amongst the health professionals is an effective and tested undertaking in introducing EBP in developing countries such as the Philippines.
\end{abstract}

Keywords: continuing education, developing countries physical therapy, medicine, knowledge and skills

\section{Background}

Evidence-based practice (EBP) is defined as the integration of best research evidence, clinical expertise, and patient values. ${ }^{1}$ The aim of using evidence-to-guide practice is to support effective practice by using evidence-based patient management strategies which are known to result in best patient care as shown by Schreiber and Stern. ${ }^{2}$ Thus, the concepts of EBP, which include formulating a focused clinical question, searching and accessing the literature to identify the best research evidence, assessing the validity of the evidence (critical appraisal), and applying the evidence to actual patient scenarios, have been introduced and evaluated in the training of health professionals, particularly among medical doctors in developed countries. . $^{3,4}$

The application of EBP has been integral in the health system for several years now. ${ }^{5}$ Within the last decade, the focus of research was the review of evidence in the form of clinical guidelines, systematic reviews, meta-analyses, and evidence summaries to arrive at recommendations to guide health professionals in practice. ${ }^{6-9}$ More recently, research has been in the implementation of these recommendations into practice. ${ }^{10-12}$ Strategies addressing barriers such as lack of knowledge and skills in EBP, lack of access, and local contextual barriers have been identified and tested amongst a range of health professionals in various workplace settings. ${ }^{10-12}$
Correspondence: Janine Margarita Dizon Center for Health Research and Movement Science, University of Santo Tomas, Espana, Manila, 1018 Philippines Tel +632406 I6II or +639088687110 Fax +632740 9713

Email janine.dizon@mymail.unisa.edu.au 
Whilst EBP activities have taken place in developed countries such as Australia, Canada, the UK, and the US, the principle of getting research evidence into practice is still in its infancy in developing countries. It has been recognized that EBP is relevant to developing countries particularly in order to maximize the use of scarce health resources (ensuring that no money is put to waste) and achieve effective patient outcomes (considering health and safety) and efficient health systems. These benefits can filter through to reducing poverty-related conditions and result in better health outcomes. ${ }^{13-18}$ Whilst these benefits of using EBP principles in practice have been clearly established, the growth of EBP in developing countries has been slow. ${ }^{19}$ Country-by-country variations require strategies tailored to the local context settings to facilitate the use of EBP. One of the most important and basic strategies is the provision of an EBP training in order to cultivate a culture of research and to build EBP capacity among health professionals and organizations..$^{14,17,18}$

To address the gaps in the literature, a tailored EBP training program was developed for a group of health professionals in a developing country (the Philippines). The training program consisted of the fundamental five steps in EBP (asking the right question, acquiring, appraising, applying, and assessing the evidence) and strategies addressing the local context needs (format and delivery of the training program, online support, and use of a recommendation checklist). ${ }^{13,20}$ The training program has been tested in a randomized controlled trial (RCT; control group did not receive any intervention and was waitlisted for the training) and was found to be significantly effective in improving knowledge, skills, attitudes, and behavior to EBP after the training (immediate and 3 months post-training). ${ }^{20}$ The EBP training program was identified as appropriate and relevant to be conducted in other groups of health professionals in the country in order to build capacity in EBP and improve knowledge and skills. Thus, this study was undertaken to assess the impact of the EBP training amongst other health professionals in the Philippines.

\section{Materials and methods Ethics}

Ethical approval was obtained from the University of Santo Tomas, College of Rehabilitation Sciences Research Ethics Committee.

\section{Study design}

We conducted a "before and after study" to evaluate the effectiveness of a 1-day, face-to-face EBP training program designed to improve knowledge and skills in EBP amongst health professionals. Pre-training assessments were undertaken on the scheduled date of training, before commencing with the lectures and activities. Immediately after the training, post-training knowledge and skills in EBP were measured.

There was no need for an experimental study with a control group as a previous RCT by Dizon et al had reported that the EBP training program (conducted in this study) resulted in significant improvements in knowledge, skills, attitudes, and behavior as compared with a waitlist control group. Large improvement in knowledge and skills were reported in the RCT (effect size was 0.74 for pre-training to immediate post-training). ${ }^{20}$

\section{Participants}

Health professionals working in hospitals in Manila were recruited to take part in this study. As there was limited funding to run the study, one government and one private hospital were included in the study.

\section{Study setting}

The EBP training was conducted in the hospitals' conference rooms where laptops and internet access were set up.

\section{Intervention}

The EBP training program is a 1-day face-to-face training in the form of lectures and practical sessions and using small group discussions to facilitate learning (Table S1). In addition to face-to-face training, the program consists of a link to online support (https://www.unisa.edu.au/Research/Sansom$\underline{\text { Institute-for-Health-Research/Research-at-the-Sansom/ }}$ Research-Concentrations/Allied-Health-Evidence/QualityCare/EBPPhil/) and an EBP Checklist (Table S2) provided to the health professionals as a "take home" strategy. These strategies were designed to promote the use of the knowledge and skills in EBP after the training. Details of the EBP training intervention have been published previously. ${ }^{13,20}$

\section{Outcome measures}

The Fresno test of competency was used to measure EBP knowledge and skills among medical doctors. The Fresno test consists of clinical scenarios where a focused question needs to be formulated, and the following identified: sources of evidence, best evidence to answer the question, validity of the evidence, applicability of the evidence, and questions related to some statistical interpretations. ${ }^{21}$ The Fresno test has been reported to be valid and reliable in measuring these domains (intraclass correlation coefficient [ICC]: 0.76-0.98 
with a Cronbach's $\alpha$ of 0.88 ). The test is scored using a grading rubric, with a total of 17 questions and 212 points.

The Adapted Fresno test (AFT) ${ }^{22}$ was used to measure EBP knowledge and skills among the allied health professionals (physical therapists and occupational therapists). The AFT was adapted from the Fresno Test in medicine and has been reported to have good psychometric properties, measuring knowledge and skills after undergoing EBP training. ${ }^{22}$

There are two versions of the test (different clinical scenarios for each test) and ICC scores for subtests were, version 1: ICC: $0.80-0.96$; version 2: 0.68-0.94 and ICC for total scores were version 1: ICC: 0.96 ; version 2: ICC: 0.91 . Internal consistency was acceptable (Cronbach's $\alpha=0.74$ ). The test is scored using a grading rubric with a total of seven questions and 150 points. We used version 1 for the pre-training assessment and version 2 for the post-training assessment.

Both the Fresno Test and the AFT measure the health professionals' ability to formulate a question from a clinical scenario, identify appropriate search terms and relevant sources of evidence, identify the basis for assessment of methodological strengths of the evidence, and assessment of clinical relevance, applicability, and magnitude of effects. ${ }^{21,22}$

\section{Data analysis}

Data was analyzed using SAS software (v9.2; SAS Institute, Cary, NC, USA). Descriptive statistics (measures of central tendency and variability) were computed as well as within group changes from pre- to post-training (median changes, 95\% confidence interval, and associated $P$-values) in knowledge and skills using either the Fresno test or the Adapted Fresno test.

\section{Results}

A total of 31 health professionals from two hospitals in Manila, the Philippines participated in the study. There were 14 medical doctors and 17 allied health professionals. Characteristics of the participants are presented in Tables 1 and 2. Most of the participants in the training were $<30$ years of age and had $<5$ years of practice. Very few had been exposed to training in EBP (more medical doctors than allied health professionals).

Knowledge and skills in EBP significantly improved from pre- to post-training, in both groups (Tables 3 and 4). The improvements were larger amongst the allied health professionals compared with the medical doctors.

\section{Discussion}

In this study, we report on the effects of an EBP training program conducted among health professionals in the Philippines.
Table I Characteristics of the participants $(n=3 \mid)$

\begin{tabular}{|c|c|}
\hline Characteristics & n (\%) \\
\hline \multicolumn{2}{|l|}{ Age (years) } \\
\hline$<30$ & $23(74 \%)$ \\
\hline $30-39$ & $4(13 \%)$ \\
\hline $40-49$ & $0(0 \%)$ \\
\hline $50-59$ & $3(10 \%)$ \\
\hline $60+$ & I (3\%) \\
\hline \multicolumn{2}{|l|}{ Sex } \\
\hline Female & I 5 (48\%) \\
\hline Male & $16(52 \%)$ \\
\hline \multicolumn{2}{|l|}{ Years of practice } \\
\hline$<1$ & $6(19 \%)$ \\
\hline $\mathrm{I}-4$ & $14(45 \%)$ \\
\hline $5-9$ & $4(13 \%)$ \\
\hline $10-14$ & $2(6 \%)$ \\
\hline $15-19$ & I (3\%) \\
\hline $20-24$ & $2(6 \%)$ \\
\hline $25-29$ & I (3\%) \\
\hline $30-34$ & $0(0 \%)$ \\
\hline $35-39$ & $0(0 \%)$ \\
\hline $40+$ & I (3\%) \\
\hline \multicolumn{2}{|l|}{ Affiliation } \\
\hline Private hospital & I 7 (55\%) \\
\hline Government hospital & $14(45 \%)$ \\
\hline \multicolumn{2}{|l|}{ Type of health professional } \\
\hline $\begin{array}{l}\text { Medical doctors ( } 5 \text { medical consultants } \\
\text { and } 9 \text { medical residents) }\end{array}$ & $14(45 \%)$ \\
\hline $\begin{array}{l}\text { Allied health professionals ( } 15 \text { physical therapists } \\
\text { and } 2 \text { occupational therapist) }\end{array}$ & $17(55 \%)$ \\
\hline \multicolumn{2}{|l|}{ EBP exposure } \\
\hline \multicolumn{2}{|l|}{ With EBP exposure (workshops in EBP) } \\
\hline Medical doctors & $3(10 \%)$ \\
\hline Allied health professionals & I (3\%) \\
\hline \multicolumn{2}{|l|}{ No EBP exposure } \\
\hline Medical doctors & II (35\%) \\
\hline Allied health professionals & $16(52 \%)$ \\
\hline
\end{tabular}

Abbreviation: EBP, evidence-based practice.

The training resulted in improved capacity in EBP among the medical doctors and allied health professionals in terms of knowledge and skills. Our findings are similar to the findings of a previous work by one of the authors of this study. ${ }^{20}$ However, the previous study conducted the EBP training for only one group of health professionals (physical therapists). This current study tested the EBP training not only amongst

Table 2 Demographic characteristics of the medical doctors and allied health professionals

\begin{tabular}{llll}
\hline Participants & Sex & Age* (years) & $\begin{array}{l}\text { Years of } \\
\text { practice* }\end{array}$ \\
\hline $\begin{array}{l}\text { Medical doctors } \\
(\mathrm{n}=14)\end{array}$ & $\begin{array}{l}\text { Females }=7 \\
\text { Males }=7\end{array}$ & $28.5(26.0-67.0)$ & $3.0(0.5-40.0)$ \\
$\begin{array}{l}\text { Allied health } \\
\text { professionals }(\mathrm{n}=17)\end{array}$ & $\begin{array}{l}\text { Females }=8 \\
\text { Males }=9\end{array}$ & $25.0(22.0-36.0)$ & $2.0(0.0-13.0)$ \\
\hline Note: *Age and years of practice reported as median and range.
\end{tabular}


Table 3 Changes in EBP knowledge and skills of the medical doctors

\begin{tabular}{llll}
\hline $\begin{array}{l}\text { Knowledge and } \\
\text { skills in EBP (Fresno } \\
\text { test of EBM) }\end{array}$ & $\begin{array}{l}\text { Median } \\
\text { (range) }\end{array}$ & $\begin{array}{l}\mathbf{9 5 \%} \\
\text { confidence } \\
\text { interval }\end{array}$ & P-value \\
\hline Pre-training & $34.5(20.0-48.0)$ & $30.0-40.2$ & $<0.05^{*}$ \\
Post-training & $54.0(38.0-79.0)$ & $46.0-61.8$ & - \\
Change & $19.0(0-38)$ & $14.6-23.5$ & - \\
\hline
\end{tabular}

Notes: *Statistically significant difference in pre- and post-training knowledge and skills; $P$-value $\leq 0.05$.

Abbreviations: EBM, evidence-based medicine; EBP, evidence-based practice.

physical therapists, but also included medical doctors and occupational therapists, and similarly, had significant gains in EBP knowledge and skills.

Our study population was composed of young health professionals as many health professionals, particularly allied health professionals, migrate to other countries as there are limited work opportunities in this country. The same demographic has been reported on in a survey and a RCT conducted by one of the authors of this study. ${ }^{20,23}$ As such, most of the health professionals in our study have been in practice for not more than 5 years.

With the increased drive to introduce and use evidence in practice most especially in developing countries, our study provides useful information regarding potential strategies to commence EBP activities. It is widely recognized that developing countries lack research culture and are largely dependent on colleagues and textbooks for information regarding practice. ${ }^{14-19}$ In a descriptive survey conducted among physical therapists in the Philippines, the most common source of evidence and information informing their treatment decisions were recommendations from colleagues (particularly doctors) and undergraduate education (lectures and textbooks). ${ }^{23}$ Evidence from tested research was not a common source of information among the physical therapists. To shift from this current practice culture to a more evidencebased culture is very challenging. Changing from usual practice behavior of asking colleagues and reading textbooks

Table 4 Changes in EBP knowledge and skills of the allied health professionals

\begin{tabular}{llll}
\hline $\begin{array}{l}\text { Knowledge and skills } \\
\text { in EBP (Adapted }\end{array}$ & $\begin{array}{l}\text { Median } \\
\text { (range) }\end{array}$ & $\begin{array}{l}\mathbf{9 5 \%} \\
\text { confidence } \\
\text { interval }\end{array}$ & P-value \\
\hline Pre-training test of EBP) & $30.0(5.0-37.0)$ & $22.6-31.6$ & $<0.05^{*}$ \\
Post-training & $66.0(53.0-93.0)$ & $51.3-71.6$ & - \\
Change & $39.0(20.0-57.0)$ & $32.7-38.5$ & - \\
\hline
\end{tabular}

Notes: *Statistically significant difference in pre- and post-training knowledge and skills; $P$-value $\leq 0.05$.

Abbreviation: EBP, evidence-based practice. to searching for the current best research evidence in making decisions regarding a patient's case and goals takes time. Several barriers have been reported in undertaking behavior change in implementing principles of EBP such as individual constraints, lack of knowledge and skills in EBP, practice setting, lack of organizational support, and lack of time, amongst others. ${ }^{20,24-26}$ Therefore, to address these barriers, careful planning and identification of effective strategies are critical. Michie et al identified several domains needing to be considered in implementing EBP. ${ }^{27}$ Knowledge and skills are two of the domains needed to be addressed first, as these are a major barrier in EBP. Providing the health professionals with the fundamental knowledge and skills in EBP creates a clear understanding of the concepts of EBP (as oppose to hearing about the misconceptions regarding EBP) and presumably leads to a more positive attitude towards the use of EBP in practice. ${ }^{27}$

We recognize that whilst post-training knowledge and skills improved significantly amongst the health professionals in our study, training to improve knowledge and skills in EBP does not directly result in practicing in an evidence-based manner. Changing from current practice to an EBP manner requires more than just basic training. There are more domains of influence, such as beliefs about capabilities and consequences, motivation and goals, environmental context, and resources, amongst many others. ${ }^{27}$ As there are quite a number of domains of influence, more strategies need to be undertaken and evaluated to fully adopt an EBP behavior.

We also recognize that to fully adopt a culture of EBP, training should be integrated into the undergraduate curriculum. Currently, there are very few teachers in the Philippines equipped with the capacity to teach EBP amongst students in the health professions. Providing EBP training to health professionals is a strategic "train-the-trainer" approach. Building the capacity of the health professionals in EBP enables them to be future educators to undergraduate students in the health professions.

\section{Limitations}

The sampling frame and the limited funding did not allow us to include more health professionals in this study.

\section{Conclusion}

EBP training in our study resulted in significant gains in knowledge and skills among the health professionals involved. The EBP training used in this study has the potential to be useful to various groups of health professionals. 


\section{Acknowledgment}

This project has been funded in part by the Philippine Council for Health Research and Development.

\section{Disclosure}

The authors report no conflicts of interest in this work.

\section{References}

1. Sackett DL, Straus SE, Richardson SW, Rosenberg W, Haynes BR. Evidence-based Medicine: How to Practice and Teach EBM. Edinburgh: Churchill Livingstone; 2000.

2. Schreiber J, Stern P. A review of the literature on evidence-based practice in physical therapy. Internet J Allied Health Sci Pract. 2005;3:4.

3. Coomarasamy A, Khan K. What is the evidence that postgraduate teaching in evidence based medicine changes anything? A systematic review. Learn Pract. 2004;329(23):1-5.

4. Shaneyfelt T, Baum K, Bell D, et al. Evidence based practice: A systematic review. J Am Med Ass. 2006;296(9):1116-1127.

5. Taylor R, Reeves B, Ewings P, Taylor R. Critical appraisal skills training for health professionals: a randomized controlled trial. BMCMed Educ. 2004:4:30

6. The Cochrane Library. Available from: http://www.thecochranelibrary. com/details/browseReviews/4536611/Implementation-strategies.html. Accessed March 1, 2013.

7. Scottish Intercollegiate Guidelines Network [homepage on the Internet]. Available from: http://www.sign.ac.uk. Accessed March 1, 2013.

8. National Guideline Clearinghouse [homepage on the Internet]. Available from: http://www.guideline.gov. Accessed March 1, 2013.

9. National Health and Medical Research Council [homepage on the Internet]. Available from: http://www.nhmrc.gov.au/guidelines. Accessed March 1, 2013.

10. Wensing M, Van der Weijden T, Grol R. Implementing guidelines and innovations in general practice: which interventions are effective? Brit J Gen Pract. 1998;48:991-997.

11. Grimshaw JM, Eccles MP, Lavis JN, Hill SJ, Squires JE. Knowledge Translation of Research Findings. Implement Sci. 2012;7:50.

12. Hillier S, Grimmer-Somers K, Merlin T, et al. FORM: an Australian method for formulating and grading recommendations in evidencebased clinical guidelines. BMC Med Res Methodol. 2011;11:23.
13. Dizon J, Grimmer-Somers K, Kumar S. Study protocol, effectiveness of the tailored EBP training program for Filipino physiotherapists: a randomized controlled trial. BMC Med Educ. 2011;11:14.

14. Sutcliffe S, Court J. A Toolkit for Progressive Policymakers in Developing Countries. London: Overseas Development Institute. 2006;1-59.

15. Siddiqi K, Newell J, Robinson M. Getting evidence into practice: what works in developing countries? Int J Qual Health Care. 2005;17(5): 447-453.

16. Soltani A, Moayyeri A, Raza M. Impediments to implementing evidence-based mental health in developing countries. Evid Based Ment Health. 2004;7:64-66.

17. McMichael C, Waters E, Volmink J. Evidence-based public health: what does it offer developing countries? J Public Health. 2005;27(2): 215-221.

18. Chinnock P, Siegfried N, Clarke M. Is evidence-based medicine relevant to the developing world? PLoS Med. 2005;2(5):e107.

19. Bradley H, Gilham D. Collaborative strategies to promote evidence based practice in a developing country. JWorld Univ Forum. 2008;1(5): 83-87.

20. Dizon J, Grimmer K, Kumar S, et al. Effectiveness of the tailored evidence based practice training program for Filipino physical therapists. BMC Med Educ. In press 2013.

21. Ramos K, Schafer S, Tracz S. Validation of the Fresno test of competence in evidence based medicine. Learn Pract. 2003;326:319.

22. McCluskey A, Bishop B: The Adapted Fresno Test of competence in evidence based practice. J Cont Educ Health Prof. 2009;29(2):119-126.

23. Dizon J, Grimmer-Somers K, Kumar S. A survey of physical therapists in Metro Manila, Philippines: profile and bases for selection of treatment. Int J Stud Res. 2012 under review.

24. Jette D, Bacon K, Batty C, et al. Evidence-based practice: beliefs, attitudes, knowledge, and behaviors of physical therapists. Phys Ther. 2003;83(9):786-805.

25. Melnyk B, Fineout-Overholt E, Feinstein N, Sadler L, GreenHernandez C. Nurse practitioner educators' perceived knowledge, beliefs and teaching strategies regarding evidence-based practice: implications for accelerating the integration of evidence-based practice into graduate programs. J Prof Nurs. 2008;24(1):7-13.

26. Grol R, Grimshaw J. From best evidence to best practice: effective implementation of change in patients' care. Lancet. 2003;362: 1225-1230.

27. Michie S, Johnston M, Abraham C, Lawton R, Walker A. Making psychology theory useful for implementing evidence based practice: a consensus approach. Qual Safe Health Care. 2005;14:26-33. 


\section{Supplementary materials}

Table SI Training outline

\begin{tabular}{|c|c|c|c|}
\hline Schedule & Topic & Strategy & Participant's output \\
\hline \multicolumn{4}{|l|}{ Activities } \\
\hline 08:30-09:00 & Introduction to EBP & Lecture & \\
\hline $09: 00-09: 45$ & Hierarchy of evidence and study designs & Lecture & \\
\hline $09: 45-10: 00$ & Break & & \\
\hline \multirow[t]{4}{*}{$10: 00-10: 30$} & PICO formulation & Lecture on drafting PICO & Own PICO \\
\hline & & Practical session on: & \\
\hline & & a) Drafting PICO from a case & \\
\hline & & b) Drafting own PICO & \\
\hline $10: 30-11: 15$ & Designing the search & Lecture-demo & Own search strategy \\
\hline $11: 15-12: 00$ & Conducting the search & Practical session & Acquire evidence \\
\hline$|2: 00-0|: 30$ & Lunch & & \\
\hline \multirow[t]{2}{*}{$01: 30-03: 00$} & Appraising the evidence & Lecture & Appraised paper \\
\hline & & Practical session & \\
\hline 03:00-03:15 & Break & & \\
\hline \multirow[t]{3}{*}{$03: 15-04: 30$} & What does the evidence say and how & Lecture & Answer to own PICO \\
\hline & applicable is it? & Practical session & \\
\hline & How can it be applied using the EBP checklist? & & \\
\hline \multirow[t]{2}{*}{ 04:30-05:00 } & Post-program knowledge, skills, and attitudes & Adapted Fresno test and answer & \\
\hline & assessment & evaluation questions & \\
\hline
\end{tabular}

Notes: PICO, patient problem or population (P), intervention (I), comparison (C) and outcome(s) (O).

Abbreviation: EBP, evidence-based practice.

Table S2 EBP Checklist

Recommendation for applying the findings

Clinical relevance or applicability

Yes

No

- Is the population similar to your patient case and values?

- Was the intervention described in detail for you to replicate?

- Do you have the skills and facilities (equipment/venue) to apply the intervention?

Validity of the evidence-base

- Is the study valid based on the results of the appraisal?

- Were outcome measures valid?

- Were other relevant factors considered?

Magnitude of effects or clinical impact

- Are findings clinically significant?

- What are the expected effects?

Applicability

Based on the clinical relevance, validity, and magnitude of effects, are you confident in applying the findings to your own patient?

Barriers to applying the evidence

Given that the findings are clinically relevant, valid, and that expected effects are reproducible and applicable, what would make it difficult for you to apply the findings to your patient?

Strategies to address barriers

What are your suggestions to address the barriers? (please identify realistic and doable strategies)

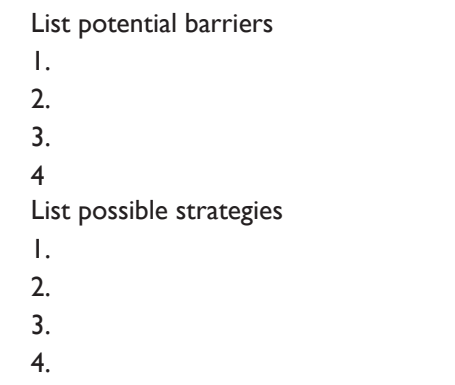

Advances in Medical Education and Practice

Dovepress

\section{Publish your work in this journal}

Advances in Medical Education and Practice is an international, peerreviewed, open access journal that aims to present and publish research on Medical Education covering medical, dental, nursing and allied health care professional education. The journal covers undergraduate education, postgraduate training and continuing medical education including emerging trends and innovative models linking education, research, and health care services. The manuscript management system is completely online and includes a very quick and fair peer-review system. Visit http://www.dovepress.com/testimonials.php to read real quotes from published authors.

Submit your manuscript here: http://www.dovepress.com/advances-in-medical-education-and-practice-journal 